\title{
Temporal coding in conditioned inhibition: Retardation tests
}

\author{
DANIEL C. BURGER \\ State University of New York, Binghamton, New York \\ JAMES C. DENNISTON \\ Appalachian State University, Boone, North Carolina \\ and \\ RALPH R. MILLER \\ State University of New York, Binghamton, New York
}

\begin{abstract}
Two lick suppression experiments with rats were conducted in order to determine the nature of the temporal information that is encoded as a result of Pavlovian conditioned inhibition training (conditioned stimulus $\{\mathrm{CS}\} \mathrm{A} \rightarrow$ unconditioned stimulus $\{\mathrm{US}\} / \mathrm{AX} \rightarrow$ noUS). After inhibition training, the conditioned inhibitor $(\mathrm{X})$ was paired with the US in order to measure inhibition, as assessed through retarded behavioral control by CS X. Three temporal relationships were manipulated: the A-US interval, the X-A interval of inhibition training, and the X-US interval of the retardation test pairings. Retardation was greatest when the X-US temporal relationship matched the time at which the US was expected (but not delivered) on the $\mathrm{X}-\mathrm{A}$ inhibition training trials. Thus, the present experiments provide evidence with retardation tests that, during conditioned inhibition training, subjects encode the temporal location of the omitted US relative to the inhibitory CS. These findings complement those of previous studies using summation tests of conditioned inhibition (Barnet \& Miller, 1996; Denniston, Blaisdell, \& Miller, 1998; Denniston, Cole, \& Miller, 1998).
\end{abstract}

A conditioned inhibitor is usually conceptualized as a conditioned stimulus (CS) that signals the omission of an unconditioned stimulus (US) at a time at which the US would otherwise be expected (e.g., because of the presence of an excitatory CS). One common procedure used to produce conditioned inhibition is the treatment developed by Pavlov (1927), in which pairings of an excitatory CS (A, the inhibition training excitor) and the US are interspersed with nonreinforced compound presentations of CS X (the putative inhibitor) and CS A (i.e., A $\rightarrow$ US/ $\mathrm{XA} \rightarrow$ noUS). Typically, in such a procedure, CS X supports behavior indicative of conditioned inhibition, as evidenced through summation and retardation tests.

Although conditioned inhibition is a well-documented behavioral phenomenon, the nature of the processes that underlie it is not yet clear. That is, neither the information

Support for this research was provided by NIMH Grant 33881. Parts of this report were presented within a masters thesis submitted to SUNYBinghamton by D.C.B., who thanks the members of his thesis committee, Patricia DiLorenzo and Peter Gerhardstein, for their contributions to earlier versions of this paper. We also thank Francisco Arcediano, Raymond Chang, Martha Escobar, and Hernan Savastano for comments on an earlier version of this paper. Furthermore, we thank James Esposito and Nancy Salpepi for their assistance in collection of the data. Correspondence concerning this article should be addressed to R. R. Miller, Department of Psychology, SUNY-Binghamton, Binghamton, NY 13902-6000 (e-mail: rmiller@binghamton.edu). encoded nor the mechanism used by animals to attenuate (i.e., inhibit) a response is fully understood. One framework that potentially illuminates some of the representational aspects of inhibitory behavioral control is the temporal coding hypothesis (e.g., Matzel, Held, \& Miller, 1988; Miller \& Barnet, 1993; Savastano \& Miller, 1998). The temporal coding hypothesis incorporates the following four tenets. (1) Contiguity is sufficient for the formation of an association between two events. (2) The temporal relationship between each pair of events is encoded as part of the acquired association (as a temporal map; Honig, 1981) - that is, the temporal relationship is not merely a catalyst for the formation of the association. (3) This temporal information is critical in determining the nature, timing, and magnitude of responding to a CS. (4) Temporal information from different phases of training can be integrated when the temporal maps of each phase contain common elements (or when multiple stimuli are presented at test). Separately if not conjointly, the first three tenets of the temporal coding hypothesis have been previously stated by many earlier researchers (e.g., Pavlov, 1927; Smith, 1968); it is the fourth tenet that is novel and is further tested in the present research. Numerous studies have been conducted to examine the integration tenet and have yielded data suggesting that subjects encode a temporal relationship between two stimuli (e.g., a CS and a US) that were never paired, provided that each stimulus has 
been paired with a common (mediating) stimulus (e.g., Barnet, Arnold, \& Miller, 1991; Barnet, Cole, \& Miller, 1997; Cole, Barnet, \& Miller, 1995; Matzel et al., 1988). Thus, not only can subjects learn that an excitatory CS signals an impending US and when, relative to the CS, the US will occur through CS-US pairings; they can also learn such relationships through mediation by a common element (Tenet 4). Notably, each of the demonstrations of temporal integration cited above used some form of secondorder conditioning or sensory preconditioning.

Pavlovian conditioned inhibition affords the opportunity to examine temporal integration in a different situation, thereby speaking to the generality of the temporal integration tenet. That is, in Pavlovian conditioned inhibition training, a CS is made excitatory by pairings with the US, and on independent trials the target inhibitor is paired with this excitatory CS in the absence of the US. Hence, there are no direct pairings of the inhibitor with the US. Any encoded temporal relationship between the inhibitor and the US must result from integration of the temporal map of the relationship between the excitatory CS and the US with the temporal map of the relationship between the inhibitor and the excitatory CS. There have recently been several reports of observations from studies of conditioned inhibition suggesting that subjects learn not only that a previously expected US will be omitted, but also when the US would have been otherwise expected (Barnet \& Miller, 1996; Denniston, Blaisdell, \& Miller, 1998; Denniston, Cole, \& Miller, 1998; see also Savastano \& Miller, 1998, for a summary). However, these experiments demonstrating temporal coding in conditioned inhibition used only summation tests, which are but half of the standard complement of tests required to certify the existence of conditioned inhibition(Rescorla, 1969; see also Hearst, 1972). What is needed in addition to a summation test is a retardation test.

In an experiment that uses a summation test for conditioned inhibition, after inhibition training, the putative inhibitor (CS X) and a transfer excitor (CS T, which has previously been independently paired with the US) are presented in compound to the subjects during testing. If $\mathrm{CS} \mathrm{X}$ is a conditioned inhibitor, responding to the compounded CSs (TX) is decreased relative to that observed upon presentation of CS T alone. Presumably, CS T has a positive response potential because presentation of CS T alone elicits a relatively strong conditioned response. CS X might be conceptualized as having a negative response potential (not necessarily implying a negative associative strength) if it comes to attenuate responding to the transfer excitor (CS T), relative to a control condition in which CS X had not undergone inhibitory training. When CSs T and X are presented in compound, their respective positive and negative response potentials appear to summate. Therefore, the conditioned response elicited by the TX compound is lower than the conditioned response following presentation of CS T alone. Passing a summation test for conditioned inhibition, however, is not sufficient to certify that a stimulus is a conditioned in- hibitor (Hearst, 1972; Rescorla, 1969). The decrement in responding to the TX compound might be explained alternatively in terms of (1) stimulus generalization decrement between training with the transfer excitor alone and testing with the compound test stimulus, (2) negative occasion setting, or (3) inhibition training's increasing attention to CS X so that it more strongly distracts the subject from CS T. Notably, the interactions between conditioned inhibitors produced and tested with different temporal parameters in the experiments of Barnet and Miller (1996), Denniston, Blaisdell, and Miller, (1998), and Denniston, Cole, and Miller (1998) make implausible the first and third alternative interpretations of their summation data. Nevertheless, evidence from retardation tests that Pavlovian inhibition training encodes the time of US omission would lend convergent support to the published reports, based on summation tests, of temporal encoding and integration in Pavlovian conditioned inhibition.

Toward testing the predictions of the temporal coding hypothesis concerning conditioned inhibition, Barnet and Miller (1996), Denniston, Blaisdell, and Miller (1998), and Denniston, Cole, and Miller (1998) have shown, with summation tests following Pavlovian inhibition training (i.e., $\mathrm{A} \rightarrow \mathrm{US} / \mathrm{XA} \rightarrow$ noUS), that conditioned inhibition is maximal when the inhibitor (CS X) signals omission of the US (based on the A-US and X-A temporal intervals) at the same temporal location as the transfer excitor (CS T) signals presentation of the US (based on the T-US temporal interval). Alternatively stated, if the omission of the US following CS X was "expected" at the same moment on the temporal map as the "expected" presence of the US following CS T, attenuation of responding to CS T by CS $\mathrm{X}$ was maximal. However, the Barnet and Miller experiments and the Denniston et al. experiments were all performed only with summation tests, so only half of the two-test strategy, as proposed by Rescorla (1969), has been completed.

The present series of experiments completes the more general project of examining temporal coding in conditioned inhibition by providing a retardation test, following manipulation of the following three temporal intervals: (1) the A-US interval and (2) the X-A interval- both of inhibition training - and (3) the X-US interval of the retardation test pairings. In Experiment 1, Intervals 1 and 3 (A-US and X-US) were manipulated, and in Experiment 2, Intervals 2 and 3 (X-A and X-US) were manipulated. Both experiments were performed using about the same design as that in the Denniston, Blaisdell, and Miller (1998) and Denniston, Cole, and Miller (1998) experiments, except that the present experiments omitted training with a transfer excitor, which had been required for the summation tests used by Denniston et al. Although crossexperiment comparisons are not critical to interpretation of the present results, in retrospect we should have included training with a transfer excitor (despite its not being used during test in this series) in order to maintain complete equivalence of treatment with the earlier papers cited above. 


\section{EXPERIMENT 1}

In Experiment 1, two training excitors were used. CS A was presented as a delay excitor ( 0 sec between termination of A and onset of the US), and CS B was presented as a trace excitor ( $5 \mathrm{sec}$ between termination of $\mathrm{B}$ and onset of the US). In addition, two inhibitory CSs were established. CSs $\mathrm{X}$ and $\mathrm{Y}$ were separately paired with training excitors $\mathrm{A}$ and $\mathrm{B}$ (i.e., $\mathrm{X}-\mathrm{A} / \mathrm{Y}-\mathrm{B}$ ), and these compounds were never followed by the US. Such training was designed to give CSs $\mathrm{X}$ and $\mathrm{Y}$ inhibitory value. The resultant conditioned inhibition was assessed with a retardation test, which, for different groups, required that $\mathrm{X}$ or $\mathrm{Y}$ be reinforced. During the same training sessions in which $\mathrm{X}$ or $\mathrm{Y}$ was paired with the US for some groups, other groups had a third (control) CS (Z) reinforced in order to assess the rate of acquisition by a "neutral" stimulus. We anticipated that greater inhibitory control by X (and Y) would be observed when the temporal relationship of X (or Y) to the US on the retardation test pairings matched the temporal relationship of $X$ (and $Y$ ) to the (omitted) US during inhibition training (on the basis of the A-US [or B-US] and X-A [or Y-B] intervals) than when the temporal relationships were not matched. The experiment used a $3 \times 2$ factorial design in which testing was performed with $\mathrm{X}, \mathrm{Y}$, or $\mathrm{Z}$ and the retardation test pairings of this test stimulus with the US used either a delay $(0 \mathrm{sec})$ or trace $(5 \mathrm{sec})$ relationship.

\section{Method}

\section{Subjects}

The subjects were 30 male and 30 female Sprague-Dawley rats from our own breeding colony randomly assigned to six groups $(n s=10)$. Body weight ranges were $220-363 \mathrm{~g}$ for males and 180 $245 \mathrm{~g}$ for females. The subjects were individually housed in standard hanging, stainless steel, wire-mesh cages and were kept on a 16:8-h light:dark cycle, with all experimental procedures taking place near the middle of the light cycle. The subjects were allowed free access to Purina Lab Pellets. However, 1 week prior to the beginning of the study, the subjects were placed on a progressive water deprivation schedule until they were receiving $20 \mathrm{~min}$ of water per day, given at least $1 \mathrm{~h}$ after any experimental treatment on that day. From the time of weaning to the start of the study, all the subjects were handled three times per week for $30 \mathrm{sec}$.

\section{Apparatus}

The apparatus consisted of 12 chambers, 6 each of two styles (i.e., Chamber V and Chamber R). Each animal received all training in one chamber style and testing in the opposite chamber style. This switching of chambers for testing was intended to minimize summating of any excitatory value accrued by the training context with the response potential of the target CS (X). Chamber assignments were counterbalanced within groups. Chamber V was a 27.0$\mathrm{cm}$-long box in the shape of a vertical truncated V. The chamber was $29.5 \mathrm{~cm}$ high, $21.5 \mathrm{~cm}$ wide at the top, and narrowed to $5.5 \mathrm{~cm}$ wide at the bottom. The ceiling was constructed of clear Plexiglas, and the front and back walls were black Plexiglas, whereas the side walls were stainless steel. The floor consisted of two 27.0-cm-long parallel metal plates, each $2 \mathrm{~cm}$ wide and separated by a $1.5-\mathrm{cm}$ gap. A constant-current footshock, produced by a high-voltage AC circuit in series with a 1.0-M $\Omega$ resistor, could be delivered through the metal walls and floor of the chamber. Each copy of Chamber V was housed in a separate sound- and light-attenuating environmen- tal isolation chest. The chamber was illuminated by a 7.5-W (nominal at $120 \mathrm{VAC}$, but driven at $60 \mathrm{VAC}$ ) incandescent houselight, which was mounted on the inside wall of the environmental enclosure approximately $30 \mathrm{~cm}$ from the center of the experimental chamber. The light entered the chamber primarily by reflection from the ceiling of the environmental chest.

Chamber $\mathrm{R}$ was rectangular in shape, measuring $24.0 \times 9.0 \times$ $12.5 \mathrm{~cm}(1 \times \mathrm{w} \times \mathrm{h})$. The walls and ceiling of the chamber were clear Plexiglas, and the floor was constructed of stainless steel rods measuring $0.5 \mathrm{~cm}$ in diameter and spaced $1.5 \mathrm{~cm}$ apart (center to center). The rods were connected by NE-2H neon bulbs, which allowed for the delivery of the constant-current footshock. Each copy of Chamber R was housed in a separate light- and sound-attenuating environmental isolation chamber. Each chamber was dimly illuminated by a $2-\mathrm{W}$ (nominal at $120 \mathrm{VAC}$, but driven at $60 \mathrm{VAC}$ ) incandescent houselight mounted on an inside wall of the environmental chest and located approximately $30 \mathrm{~cm}$ from center of the animal enclosure. The light intensities inside the two chambers (V and $R$ ) were approximately equal, owing to the differences in opaqueness of the walls of the chambers.

Each chamber could be equipped with a water-filled lick tube that extended about $1 \mathrm{~cm}$ into a cylindrical niche, $4.5 \mathrm{~cm}$ in diameter, $5.0 \mathrm{~cm}$ deep, left-right centered on an end wall of the chamber, with its bottom $1.75 \mathrm{~cm}$ above the floor of the apparatus. There was a horizontal photo beam detector $1 \mathrm{~cm}$ in front of the lick tube, which was broken whenever a subject placed its head into the niche to lick the tube. Three 45-W speakers on different inside walls of the isolation chests could deliver a high-frequency complex tone $(3000$ and $3200 \mathrm{~Hz}$, presented simultaneously) $8 \mathrm{~dB}$ (C-scale) above background (76 dB, produced primarily by a ventilation fan), a white noise $8 \mathrm{~dB}$ (C-scale) above background, or a click train $(6 / \mathrm{sec}) 8 \mathrm{~dB}$ (C-scale) above background. These stimuli served as CSs X, Y, and $\mathrm{Z}$, counterbalanced within groups. A buzzer, $8 \mathrm{~dB}$ (C-scale) above background, was also affixed to one of the inside walls of each chest. Chamber V had a 100-W incandescent light bulb, and Chamber R had a 25-W bulb (both nominal at $120 \mathrm{VAC}$, but driven at 75 VAC) mounted on an inside wall of the isolation chest, but outside of the conditioning chamber, near the side of the conditioning chamber. These lights, which were normally off, could be flashed $0.5 \mathrm{sec}$ on, $0.5 \mathrm{sec}$ off. The light and buzzer, counterbalanced within groups, served as CSs A and B. A 1.0-mA, 0.5-sec constant-current footshock served as the US. During training, the CSs were all $5 \mathrm{sec}$ in duration.

\section{Procedure}

See Table 1 for an outline of the experimental procedure. For each subject, all the experimental procedures (except for acclimation [Day 2], reacclimation [Days 28 and 29], and testing [Day 30]) took place in one of the two experimental chambers ( $\mathrm{V}$ or $\mathrm{R}$ ), which was designated as Context Train. Acclimation, reacclimation, and testing were conducted with each subject in the chamber style opposite that in which all the other experimental procedures took place ( $\mathrm{R}$ or $\mathrm{V}$ ), which was designated as Context Test. Chamber assignments were counterbalanced within groups.

Acclimation. On Day 1, all the subjects were acclimated to Context Train, which served to establish a baseline rate of drinking. With the lick tube inserted into the chamber, the subjects were placed into the chamber for a 1-h session, during which no nominal stimulus was presented. On Day 2, the subjects were similarly placed in Context Test for $1 \mathrm{~h}$ with the lick tube present. This latter session served to establish a baseline rate of drinking in Context Test.

Conditioned inhibition training. Lick tubes were removed from Context Train. On Days 3-26, conditioned inhibition training took place, which was identical for all the subjects, with the only exception being the physical stimuli presented, owing to the counterbalancing of the stimuli within groups. During these daily $80-\mathrm{min}$ sessions, the subjects received six of each of four trial types (for a total of 24 trials per session). The four trial types were (1) presen- 
Table 1

Design of Experiment 1

\begin{tabular}{|c|c|c|c|c|c|}
\hline Group & $\begin{array}{l}\text { Conditioned Inhibition } \\
\text { Training (All Groups) }\end{array}$ & $\begin{array}{c}\text { Retardation Test } \\
\text { Pairings }\end{array}$ & $\begin{array}{c}\text { Test CS } \rightarrow \\
\text { Expected Behavior }\end{array}$ & Mean & Adjusted Mean \\
\hline $\mathrm{X}-0$ & A-0->US/XA $\rightarrow$ noUS/ & $\mathrm{X}-\mathrm{O}_{-}>\mathrm{US}$ & $\mathrm{X} \rightarrow \mathrm{CI}$ & 1.16 & 1.13 \\
\hline $\mathrm{Y}-0$ & B--5-->US/YB $\rightarrow$ noUS & $\mathrm{Y}^{-0}->\mathrm{US}$ & $\mathrm{Y} \rightarrow \mathrm{CR}$ & 1.47 & 1.44 \\
\hline Z-0 & & $\mathrm{Z}-^{-0}>>\mathrm{US}$ & $\mathrm{Z} \rightarrow \mathrm{CR}$ & 1.94 & 1.96 \\
\hline $\mathrm{X}-5$ & & X--5-->US & $\mathrm{X} \rightarrow \mathrm{CR}$ & 1.51 & 1.52 \\
\hline Y-5 & & Y--5-->US & $\mathrm{Y} \rightarrow \mathrm{CI}$ & 0.98 & 0.96 \\
\hline $\mathrm{Z}-5$ & & Z--5-->US & $\mathrm{Z} \rightarrow \mathrm{CR}$ & 1.58 & 1.62 \\
\hline
\end{tabular}

Note-CSs A and B are conditioned excitors, CSs X and Y are conditioned inhibitors, and CS Z is a control stimulus. 0 and 5 represent the amount of time (in seconds) between CS termination and US onset (i.e., delay and trace, respectively). / represents the interspersing of trials. Mean and Adjusted Mean represent suppression in log seconds. Adjusted means have been adjusted for preCS scores on the basis of an analysis of covariance. $\mathrm{CI}$ denotes behavior indicative of conditioned inhibition, and CR denotes excitatory responding. Training and the retardation test pairings occurred in one context, whereas testing occurred in a distinctly different context.

tation of CS A, followed immediately at its termination by presentation of the US; (2) simultaneous nonreinforced presentation of CSs A and X; (3) presentation of CS B followed by the US, with a 5 -sec gap between the termination of CS B and the onset of the US; and (4) simultaneous nonreinforced presentation of CSs B and Y. Thus, there was a total of 12 reinforced and 12 nonreinforced trials per session. Trial types were presented in a pseudorandom order with an intertrial interval of $3 \pm 1.5 \mathrm{~min}$. Two different schedules were used, each beginning with one trial of each of the reinforced trial types, followed by one of each of the nonreinforced trial types. Following those 4 trials, trial types were pseudorandomly ordered, with no more than 3 reinforced or 3 nonreinforced trials occurring successively.

Retardation pairings. Retardation pairings took place in Context Train during one 60-min session on Day 27 with the lick tubes absent. The subjects received 5-sec presentations of CS X, Y, or Z. Those subjects that received training with $\mathrm{Z}$ provided a baseline for acquired suppression, against which the groups tested with putative inhibitors $\mathrm{X}$ and $\mathrm{Y}$ could be compared. The subjects in the delay groups (X-0, Y- 0 , and Z-0) received a US presentation that onset at the termination of the CS (i.e., delay conditioning). The subjects in the trace groups (X-5, Y-5, and Z-5) received a US presentation that onset $5 \mathrm{sec}$ after the termination of the CS (i.e., trace conditioning). The subjects in the delay groups received three $\mathrm{CS} \rightarrow \mathrm{US}$ pairings, whereas those in the trace condition received four CS $\rightarrow$ US pairings. The difference in number of trials was intended to better equate the strength of acquisition to $\operatorname{CS~} \mathrm{Z}$ between the delay and the trace conditions, because trace conditioning often requires more extensive training than does delay conditioning to elicit a strong conditioned response. Trials took place at $10,23,37$, and 48 min into the training session for the trace groups (an intertrial interval of $12 \pm 2 \mathrm{~min}$ ) and at 13,30 , and $48 \mathrm{~min}$ into the session for the delay condition (17- and 18-min intertrial interval). Notably, the critical planned comparisons avoided contrasting delay and trace conditions owing to the confound in number of retardation test pairings.

Reacclim ation. On Days 28 and 29, the subjects were placed into Context Test with lick tubes present for daily 60-min sessions, during which no nominal stimulus was presented. These reacclimation sessions served to reestablish a baseline rate of drinking, which might have been disrupted by the US. Times to complete the first 5 cumulative seconds of licking were recorded.

Testing. On Day 30, testing occurred during an 11-min session in Context Test with lick tubes present. Upon placement in Context Test, the time required to complete the first 5 cumulative seconds of licking was recorded for each subject. This served as each subject's baseline measure (preCS score). Any subject that did not complete its first 5 cumulative seconds of licking within its first $60 \mathrm{sec}$ in the chamber was scheduled for elimination from the study, owing to excessive fear of the context. No subject from any group was excluded from Experiment 1 because of this requirement. Upon completion of the first 5 cumulative lick seconds, the test CS was presented, and the time to complete the next 5 cumulative lick seconds was recorded; this served as the central dependent measure. A ceiling of $10 \mathrm{~min}$ was imposed on the scores recorded during the presentation of the test CS. In order to better approximate the normality assumption of parametric statistical tests, all recorded times were subjected to a log (base 10) transform.

\section{Results and Discussion}

The results of Experiment 1 indicated that greater retardation was present in Groups X-0 and Y-5, the groups for which the representation of the omitted US on the temporal map coincided with the representation of the expected US (explained below), than in Groups X-5 and Y-0. The following statistical analyses support this conclusion.

A 3 (test stimulus, $X$ vs. Y vs. Z) $\times 2$ (temporal interval during retardation test pairings, delay vs. trace) analysis of variance (ANOVA) was conducted on the preCS scores and revealed no significant differences between groups (all $F_{\mathrm{s}}<1$ ), thereby indicating that there were no appreciable group differences in readiness to drink in Context Test when no test CS was present. Thus, all differences in the test data can be attributed to the test stimulus, as opposed to the test context.

A 3 (X vs. Y vs. Z) $\times 2$ (delay vs. trace retardation test pairings) analysis of covariance (ANCOVA), with preCS scores as the covariate, was conducted on the log times to complete 5 cumulative seconds of licking in the presence of the test CS. An ANCOVA was used because there was an appreciable variability in preCS scores within groups, despite the lack of differences between groups in this measure. Moreover, the individual preCS scores were positively correlated, although not significantly so, with the CS scores. The ANCOVA revealed a main effect of test stimulus $\left[F(2,53)=12.82, M S_{\mathrm{e}}=0.15, p<.001\right]$ and an interaction $\left[F(2,53)=7.41, M S_{\mathrm{e}}=0.15, p<.002\right]$. There was no main effect of temporal interval $(p>.10)$, which was not surprising, given that we administered four retardation test pairings to the trace groups and only three retardation test pairings to the delay groups precisely to 
minimize such a main effect. Both the group mean log times and the adjusted means from the $3 \times 2$ ANCOVA are provided in Table 1.

Planned comparisons of responding to $\mathrm{X}$ and to $\mathrm{Y}$ relative to control CS $\mathrm{Z}$ within the delay condition (using the error term from the ANCOVA) found less suppression to $\mathrm{X}$ than to $\mathrm{Z}[F(1,53)=23.00, p<.001]$ and less suppression to $\mathrm{Y}$ than to $\mathrm{Z}[F(1,53)=9.03, p<.01]$. A similar analysis within the trace condition found less suppression to $\mathrm{Y}$ than to $\mathrm{Z}[F(1,53)=14.66, p<.001]$, but suppression to $X$ did not differ significantly from suppression to $\mathrm{Z}(F<1)$. In both the delay and the trace conditions, $X$ and $Y$ were numerically, if not statistically, retarded relative to control CS Z (see Table 1). The critical question was whether there were differences in retardation between $\mathrm{X}$ and $\mathrm{Y}$ as a function of temporal interval.

To assess different degrees of inhibitory control by CSs $\mathrm{X}$ and $\mathrm{Y}$ in each temporal interval condition, a 2 (test stimulus, $\mathrm{X}$ vs. $\mathrm{Y}$ ) $\times 2$ (temporal interval, trace vs. delay) ANCOVA, with preCS scores as the covariate, was conducted. This analysis revealed no main effects $\left(F_{\mathrm{S}}<1\right)$, but importantly, it did detect an interaction $\left[F(1,35)=16.80, M S_{\mathrm{e}}=0.11, p<.001\right]$. To identify the sources of the interaction, planned comparisons between suppression to $\mathrm{X}$ and to $\mathrm{Y}$ within each interval condition were conducted, using the error term from the $2 \times 2$ ANCOVA. These contrasts revealed differences between suppression to CS $\mathrm{X}$ and to CS Y in the delay condition $\left[F(1,35)=4.25, M S_{\mathrm{e}}=0.11, p<.05\right]$ and in the trace condition $\left[F(1,35)=13.94, M S_{\mathrm{e}}=0.11, p<.001\right]$. Specifically, CS X elicited less suppression (i.e., more retardation) in the delay condition, and CS Y elicited less suppression (i.e., more retardation) in the trace condition.

The present results support the temporal coding hypothesis' prediction that the temporal relationship between stimuli is part of the information encoded in conditioned inhibition training. That is, conditioned inhibition training appears to create an expectation of the US's being omitted at the specific time at which it was on the basis of its relationship with the training excitor. The hypothetical temporal maps for Experiment 1 are illustrated in Figure 1. Maximal retardation was observed when the time of US omission predicted by the inhibitor (X or Y) was the same as the time of expected US presentation based on the retardation test pairings of the inhibitors with the US. These findings specifically demonstrate that the

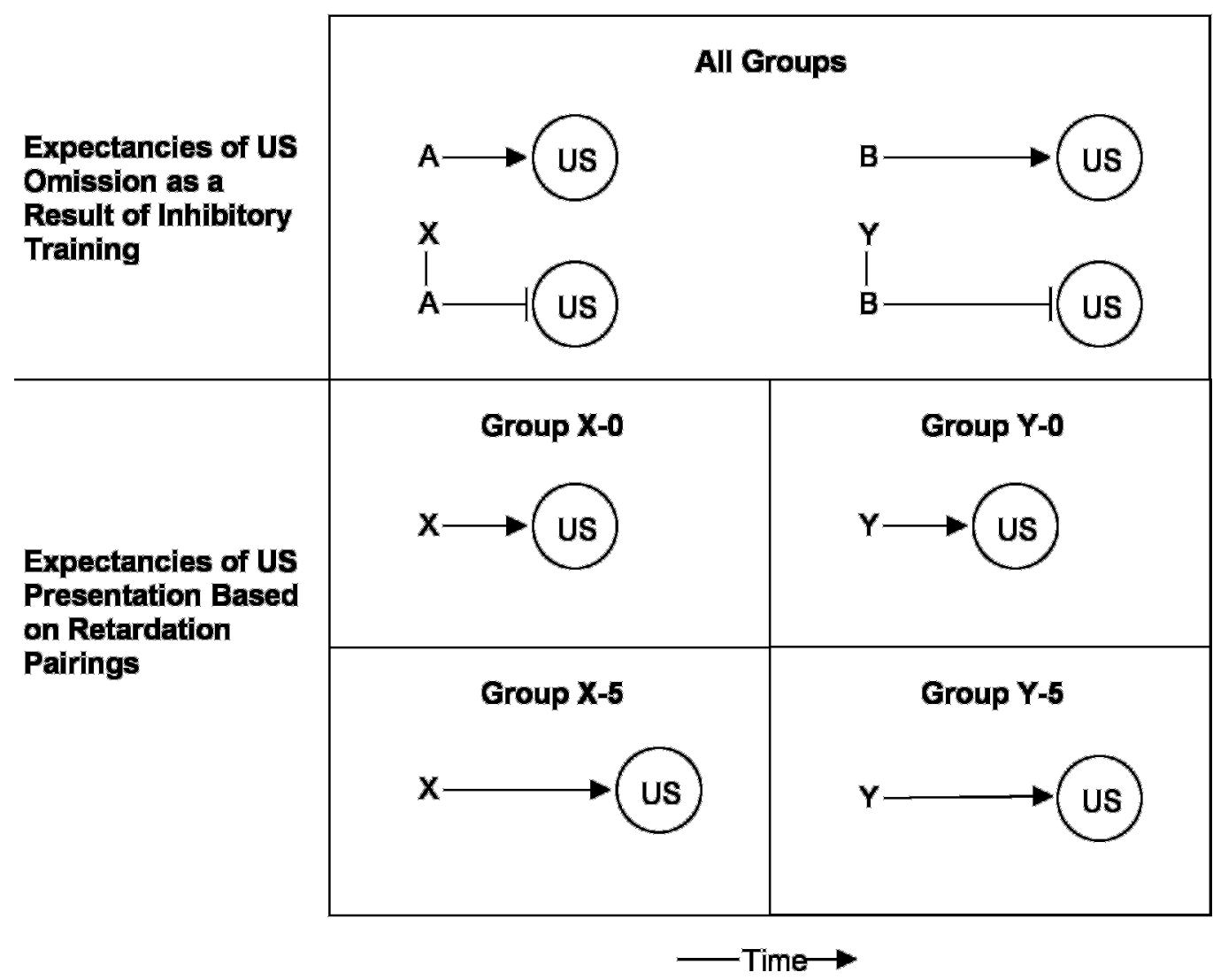

Figure 1. Hypothetical temporal maps of subjects in Groups X-0, X-5, Y-0, and Y-5 in Experiment 1. CSs A and $B$, training excitors; CSs $X$ and $Y$, potential conditioned inhibitors; US, unconditioned stimulus; horizontal line ending with a cross bar, tem poral location of expected but omitted US. All the subjects received inhibition training with CSs $\mathrm{X}$ and $\mathrm{Y}$, but for any given group retardation pairings were with only one CS (X, Y, or Z). See Table 1 . 
interval between the inhibition training excitor (CSs A and $\mathrm{B}$ ) and the US during inhibition training and the interval between the inhibitor (CSs X and Y) and the US during the retardation test pairings are important and interact in determining the degree of behavior indicative of conditioned inhibition that a CS will control. More generally, these results suggest that conditioned inhibition will be greater when, with superimposition of the temporal maps from the different trial types, the US representation activated by the inhibitor as a consequence of the retardation test pairings and the omitted US representation resulting from inhibition training are coincidental on the temporal map.

\section{EXPERIMENT 2}

To complement the findings of Experiment 1, in Experiment 2, different temporal intervals were manipulated during inhibition training. Specifically, in Experiment 2, we examined the consequences for inhibitory stimulus control of independently manipulating (1) the interval between the inhibitor and the training excitor (X-A and $\mathrm{Y}-\mathrm{A}$ ) during Pavlovian inhibition training and (2) the interval between the inhibitor and the US (X-US and $\mathrm{Y}-\mathrm{US}$ ) during retardation test pairings. In contrast to Experiment 1, only one excitor (A) was trained during the inhibitory conditioning phase, and it was always presented in a delay relationship with the US (i.e., $A \rightarrow U S$ ). Two inhibitors were trained with $\mathrm{A}$, but with different temporal arrangements. One inhibitor (Y) was trained simultaneously with CS A (i.e., YA $\rightarrow$ noUS), and the other inhibitor $(X)$ was trained with a serial relationship (i.e., $\mathrm{X} \rightarrow \mathrm{A} \rightarrow$ noUS). The retardation pairings (with CSs $\mathrm{X}, \mathrm{Y}$, and $Z$ ) occurred as in Experiment 1. Through the same reasoning as that in Experiment 1, we expected more inhibitory control by $\mathrm{X}$ and $\mathrm{Y}$ when their temporal relationships to the US on the retardation test pairings matched the temporal relationships of $\mathrm{X}$ and $\mathrm{Y}$ to the (omitted) US during inhibition training (these times were based on the A-US and X-A [or Y-A] intervals) than when these temporal relationships were unmatched.

\section{Method}

\section{Subjects and Apparatus}

The subjects were 30 male and 30 female Sprague-Dawley rats from our own breeding colony randomly assigned to one of six groups $(n \mathrm{~s}=10)$. Body weight ranges were $220-360 \mathrm{~g}$ for males and 175-285 g for females. The subjects were housed and maintained as were the subjects in Experiment 1. The apparatus was the same as that in Experiment 1, including the counterbalancing of the two chamber types within groups. Furthermore, all the stimuli used in Experiment 1, except the buzzer, were also used in Experiment 2. CS A was consistently the flashing light.

\section{Procedure}

See Table 2 for an outline of experimental procedures.

Acclimation. On Days 1 and 2, all the subjects received acclimation to Context Train and Context Test just as in Experiment 1.

Conditioned inhibition training. Lick tubes were removed from the training chambers for all training sessions and were not reinserted until reacclimation (Days 28 and 29). On Days 3-26, conditioned inhibition training took place, which was identical for all the subjects, the only exception being the physical stimuli presented, owing to the counterbalancing of CSs X and Y within groups. During each of these daily 60 -min sessions, the subjects received six of each of three trial types (for a total of 18 trials per session). The three trial types were (1) presentation of CS A for $5 \mathrm{sec}$, followed immediately by the US, which onset at the termination of CS A, (2) nonreinforced simultaneous 5-sec presentation of CSs A and Y with common onsets and terminations, and (3) nonreinforce $\mathrm{d} 5$-sec presentation of CS X, followed by a presentation of CS A, which onset at the termination of CS X. Thus, there were a total of 6 reinforced and 12 nonreinforced trials per session. Trials were presented with an intertrial interval of $3 \pm 1.5 \mathrm{~min}$. Two different running schedules were used on alternating days, each beginning with 1 reinforced trial, followed by one of each of the two nonreinforced trial types. Following those 3 trials, trial types were pseudorandomly ordered, with no more than two of any given trial type occurring consecutively.

Retardation pairings, reacclimation, and test. Retardation pairings (Day 27), reacclimation (Days 28 and 29), and testing (Day 30) were all identical to those in Experiment 1. The data from 2 subjects were eliminated from the study, one from Group X-0 and the other from Group Y-0, owing to their failure to complete $5 \mathrm{cu}-$ mulative lick seconds of preCS in less than $60 \mathrm{sec}$.

\section{Results and Discussion}

The results of Experiment 2 indicated that maximal conditioned inhibition was observed in Groups X-5 and

Table 2

Design of Experiment 2

\begin{tabular}{|c|c|c|c|c|c|}
\hline Group & $\begin{array}{l}\text { Conditioned Inhibition } \\
\text { Training (All Groups) }\end{array}$ & $\begin{array}{l}\text { Retardation Test } \\
\text { Pairings } \\
\end{array}$ & $\begin{array}{c}\text { Test CS } \rightarrow \\
\text { Expected Behavior }\end{array}$ & Mean & Adjusted Mean \\
\hline $\mathrm{X}-0$ & $\mathrm{~A}^{0}{ }^{-}>\mathrm{US} / \mathrm{XA} \rightarrow \mathrm{noUS} /$ & $\mathrm{X}-{ }^{0}->\mathrm{US}$ & $\mathrm{X} \rightarrow \mathrm{CR}$ & 1.46 & 1.53 \\
\hline $\mathrm{Y}-0$ & $\mathrm{YA} \rightarrow$ noUS & $\mathrm{Y}-0_{-}>\mathrm{US}$ & $\mathrm{Y} \rightarrow \mathrm{CI}$ & 1.20 & 1.24 \\
\hline $\mathrm{Z}-0$ & & $\mathrm{Z}-{ }^{0}->\mathrm{US}$ & $\mathrm{Z} \rightarrow \mathrm{CR}$ & 2.06 & 1.97 \\
\hline$X-5$ & & X--5-->US & $\mathrm{X} \rightarrow \mathrm{CI}$ & 1.08 & 1.05 \\
\hline Y-5 & & Y--5-->US & $\mathrm{Y} \rightarrow \mathrm{CR}$ & 1.85 & 1.85 \\
\hline Z-5 & & Z--5-->US & $\mathrm{Z} \rightarrow \mathrm{CR}$ & 2.05 & 2.05 \\
\hline
\end{tabular}

Note-CS A is a conditioned excitor, CSs X and Y are conditioned inhibitors, and CS Z is a control stimulus. 0 and 5 represent the amount of time (in seconds) between CS termination and US onset (i.e., delay and trace, respectively). / represents the interspersing of trials. Mean and Adjusted Mean represent suppression in $\log$ seconds. Adjusted means have been adjusted for preCS scores on the basis of an analysis of covariance. CI denotes behavior indicative of conditioned inhibition, and CR denotes excitatory responding. Training and the retardation test pairings occurred in one context, whereas testing occurred in a distinctly different context. 
Y-0. For these groups, the US anticipated on the basis of the retardation pairings and the US omission anticipated on the basis of the inhibition training occupied the same location on the subjects' hypothetical temporal maps. (See Figure 2 for an illustration of the temporal maps of Experiment 2.) The following statistical analyses support these conclusions.

A 3 (test stimulus, $\mathrm{X}$ vs. Y vs. Z) $\times 2$ (temporal interval, delay vs. trace) ANOVA was conducted on the preCS scores and revealed no significant differences between groups (all $F_{\mathrm{s}}<1$ ), thereby indicating no appreciable group differences in readiness to drink in Context Test.

As in Experiment 1, there was no difference in mean preCS scores between groups, but the individual preCS scores were positively correlated, although not significantly so, with the CS scores. A 3 (test stimulus) $\times 2$ (temporal interval) ANCOVA, with preCS scores as the covariate, was conducted on the log times to complete 5 cumulative seconds of licking in the presence of the test CS. This ANCOVA revealed a main effect of test stimulus $\left[\mathrm{X}, \mathrm{Y}, \mathrm{Z} ; F(2,51)=10.67, M S_{\mathrm{e}}=0.24, p<.001\right]$ and a test stimulus $\times$ temporal interval interaction $[F(2,51)=$ $\left.5.85, M S_{\mathrm{e}}=0.24, p<.01\right]$, but no main effect of tempo- ral interval during the retardation test pairings $[F(1,51)<$ $1]$. Both the group means and the adjusted means from the $3 \times 2$ ANCOVA are presented in Table 2. Planned comparison of responding to $\mathrm{X}$ and to $\mathrm{Y}$ relative to control CS Z within the delay condition, using the error term from the ANCOVA, found less suppression to $Y$ than to $\mathrm{Z}[F(1,51)=10.41, p<.01]$ and a nonsignificant tendency toward less suppression to $\mathrm{X}$ than to $\mathrm{Z}[F(1,51)=$ $3.70, p<.06]$. A similar analysis within the trace condition revealed less suppression to $\mathrm{X}$ than to $\mathrm{Z}[F(1,51)=$ $20.62, p<.001]$, but no significant difference between suppression to $\mathrm{Y}$ and $\mathrm{Z}[F(1,51)=1.63, p>.20]$.

In both the delay and the trace conditions, $\mathrm{X}$ and $\mathrm{Y}$ both elicited numerically, if not statistically, less conditioned suppression than did control CS Z (see Table 2). At issue was whether $\mathrm{X}$ and $\mathrm{Y}$ differed in their relative inhibitory potential as a function of their temporal relationships to the US during the retardation test pairings (delay vs. trace). To assess the different degrees of inhibitory control by CSs $\mathrm{X}$ and $\mathrm{Y}$ in each temporal interval condition, a 2 (test stimulus, $\mathrm{X}$ vs. $\mathrm{Y}$ ) $\times 2$ (temporal interval, trace vs. delay) ANCOVA, with preCS scores as the covariate, was conducted. This test revealed an

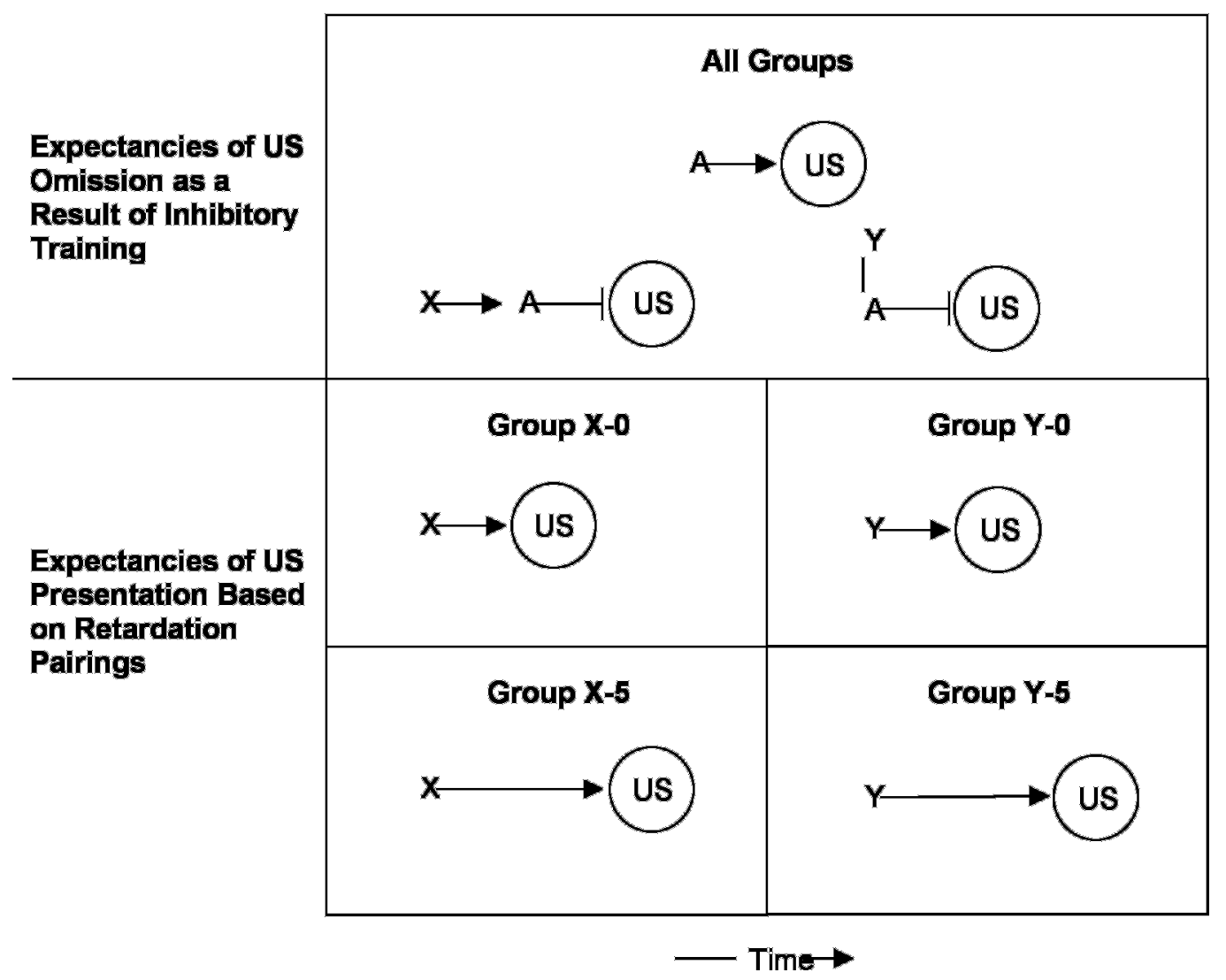

Figure 2. Hypothetical temporal maps of the subjects in Groups X-0, X-5, Y-0, and Y-5 in Experiment 2. CS A, training excitor; CSs $\mathrm{X}$ and $\mathrm{Y}$, potential conditioned inhibitors; US, unconditioned stimulus; horizontal line ending with a cross bar, temporal location of expected but omitted US. All the subjects received inhibition training with CSs $\mathrm{X}$ and $\mathrm{Y}$, but for any given group, retardation pairings were with only one CS (X, Y, or Z). See Table 2 . 
interaction $\left[F(1,33)=10.99, M S_{\mathrm{e}}=0.25, p<.003\right]$, but no main effects $\left[F_{\mathrm{s}}(1,3) \leq 2.43, p \mathrm{~s} \geq .12\right]$. To identify the sources of the interaction, planned comparisons of the suppression recorded during presentations of $\mathrm{X}$ and of $\mathrm{Y}$ within each interval condition were conducted, using the error term from the $2 \times 2$ ANCOVA. The first of the planned comparisons revealed a weak (nonsignificant) tendency toward a difference in suppression to $\mathrm{X}$ and to $\mathrm{Y}$ in the delay condition $\left[F(1,33)=1.47, M S_{\mathrm{e}}=0.25\right.$, $p<.23$ ], and the second of the planned comparisons revealed a clear difference between $\mathrm{X}$ and $\mathrm{Y}$ in the trace condition $\left[F(1,33)=12.54, M S_{\mathrm{e}}=0.25, p<.002\right]$. Specifically, in the delay condition, CS Y tended (nonsignificantly) to elicit less suppression (i.e., more retardation) than did CS X, whereas in the trace condition, CS X clearly elicited less suppression (i.e., greater retardation) than did CS Y.

The interaction in the $2 \times 2$ ANCOVA of Experiment 2 demonstrates greater conditioned inhibition in subjects that have purported representations of the US (owing to the retardation test pairings of the target CS with the US in Phase 2) and omitted US (owing to the inhibition training of Phase 1) in the same temporal location. This was determined by establishing CS A as a conditioned excitor by pairing it with the US and by establishing two other CSs (X and Y) as conditioned inhibitors through nonreinforced presentation with CS A during the same phase of training (i.e., Pavlovian conditioned inhibition training). Following all training, $\mathrm{X}$ and $\mathrm{Y}$ presumably had different temporal relationships to US omission mediated by CS A and presumably, as a function of group, differential temporal expectation of US presentation as a function of whether the retardation test pairings were delay or trace (see Figure 2). The temporal locations of the omitted US representations presumably were dependent on the temporal interval between the target CS (X or Y) and CS A (as well as the CS A-US temporal relationship, which was constant in this study). That is, on the basis of different temporal intervals between $X$ and $A$ and between $Y$ and $A$ in training, each subject should have had an expectation of an omitted US $5 \mathrm{sec}$ after CS X and immediately after CS Y. Thus, during the retardation test pairings, maximal retardation was anticipated when CS X was paired with the US in a trace relationship with a 5-sec gap between termination of CS X and onset of the US and when CS Y was paired with the US in a delay relationship with no gap between termination of CS Y and onset of the US. The present data confirmed these predictions in the trace condition and tended (nonsignificantly) toward them in the delay condition.

\section{GENERAL DISCUSSION}

The present series of experiments was conducted to complete the examination of the temporal coding hypothesis' predictions concerning what information is encoded and how the encoded information is used in behavior indicative of conditioned inhibition following Pavlovian conditioned inhibition training. These experi- ments are part of a larger series started by Barnet and Miller (1996) and continued by Denniston, Blaisdell, and Miller (1998) and Denniston, Cole, and Miller (1998). Previous experiments in this series had examined this hypothesis by varying, within Pavlovian conditioned inhibition training (A-US/XA-noUS) and summation testing with transfer excitor (CS T), (1) the training excitor-US (A-US) interval, (2) the X-A interval, (3) the T-US interval, and in testing, (4) the T-X interval. In the present series of experiments, retardation tests, rather than summation tests, were used to assess the generality of temporal specificity in Pavlovian conditioned inhibition. Hence, the T-US interval and the T-X interval (both of which involved the transfer test CS T) of these earlier studies were not potential variables in the present research. This left the A-US and A-X intervals of inhibition training to be manipulated, along with the X-US interval of the retardation test pairings. The effects of varying the A-US (and B-US) interval (Experiment 1), as well as the A-X (and A-Y) interval (Experiment 2) of inhibition training and the X-US (and Y-US) temporal interval (Experiments 1 and 2) of the retardation test pairings, were examined (see Tables 1 and 2). In so doing, the present series brings closure to the long-term project of investigating the predictions of the temporal coding hypothesis with respect to Pavlovian conditioned inhibition. Moreover, it demonstrates that evidence of temporal coding of omitted USs is not limited to summation tests of inhibition.

Experiment 1 manipulated the interval between the training excitor (A and $\mathrm{B}$ ) and the US during inhibition training, as well as the interval between the putative inhibitor ( $\mathrm{X}$ and $\mathrm{Y}$ ) and the US during the retardation test pairings, and found that greater conditioned inhibition occurred in the groups for which the temporal location of the US on the retardation test pairings corresponded to the interval between the training excitor and the US during inhibition training. Experiment 2 manipulated the interval between the putative inhibitors (X and $Y$ ) and the training excitor (A) interval during inhibition training, as well as the interval between the inhibitor (X and $\mathrm{Y}$ ) and the US during the retardation test pairings, and again found that behavior indicative of conditioned inhibition was greater in one of the two groups for which the time of the expected US and that of the expected omission of the US were matched and tended to be greater, although not significantly so, for the other group for which the two times were matched. Notably, when there was a mismatch in the temporal expectation of US omission and US presentation, some retardation (indicative of inhibition) relative to CS Z was sometimes observed. Thus, inhibition does not appear to depend on temporal matching in an all-or-none manner. Rather, inhibition merely tended toward being greater when there was a match in the two temporal expectations. Future research might well examine how parametric variations in the temporal relationship between US expectation and noUS expectation influences behavior indicative of inhibition (Holland, Hamlin, \& Parsons, 1997, did exactly this in positive oc- 
casion setting and obtained results consistent with the temporal coding hypothesis).

The present results, as well as previous experiments in this series (Barnet \& Miller, 1996; Denniston, Blaisdell, \& Miller, 1998; Denniston, Cole, \& Miller, 1998), provide support for the temporal coding hypothesis (e.g., Matzel et al., 1988; Miller \& Barnet, 1993; Savastano \& Miller, 1998), which posits that the temporal location of two stimuli, relative to each other, is encoded during training and is important in determining whether a behavior will be performed, to what degree behaviors will be performed, and the type of behavior that will be performed. Because all previous demonstrations of temporal coding in conditioned inhibition used only summation tests, the present experiments were necessary in order to certify that the same temporal control of behavior indicative of conditioned inhibition would be observed if a retardation test was used for assessment. The present observations demonstrate the generality of the earlier summation test studies that found temporal coding of US omission (Denniston, Blaisdell, \& Miller, 1998; Denniston, Cole, \& Miller, 1998). The strength of each group's conditioned response and, conversely, the degree of behavior indicative of conditioned inhibition were dependent on interaction of the various temporal intervals. The results of Experiments 1 and 2 provide evidence that, as predicted by the temporal coding hypothesis, the strongest demonstration of behavior indicative of conditioned inhibition will occur in subjects for which the hypothetical temporal maps following all phases of training (see Figures 1 and 2) have the representations of expected US presentation and US omission in the same temporal location.

Notably, the present data demonstrate only that subjects differentiate delay from trace conditioning, as opposed to encoding the actual duration of the temporal intervals between cues and outcomes. However, other work from our laboratory has clearly demonstrated that encoding of CS-US temporal relationships provides more detailed information. For example, Cole et al. (1995) observed differences in conditioned responding dependent on differences in integrated trace intervals of 5 and $10 \mathrm{sec}$.

One possible criticism of the present experiments is that, with no summation test as part of the present series, whether or not conditioned inhibition was what was causing the low level of responding in our inhibition conditions cannot be determined from the present results alone. The retardation observed in the present experiments could, instead, be a reflection of the CS-preexposure effect (Lubow \& Moore, 1959). That is, mere nonreinforced exposure to CSs X and Y prior to their being reinforced could have been responsible for the observed retardation. However, this view is implausible because any CS-preexposure effect should not be dependent on the A-US or the X-A interval, on which the responses in the present experiments clearly depended. Moreover, the present experiments used the procedures and parameters of the prior studies in our laboratory that found that the CSs purported to be the conditioned inhibitors passed summation tests for conditioned inhibition (Denniston, Blais- dell, \& Miller, 1998; Denniston, Cole, \& Miller, 1998). Conditioned stimuli exhibiting retardation owing to the CS-preexposure effect do not pass such summation tests (Rescorla, 1971).

Prior research has demonstrated that in an inhibitory training situation, subjects encode the nature of the specific omitted reinforcer (e.g., Colwill, 1991). The present research extends our understanding of what gets encoded during inhibitory training by showing that such training also encodes the temporal location of the omitted reinforcer relative to the inhibitory cue. Clearly, the temporal relationship between the inhibitor and the US reflects integration of two independently acquired (so-called) temporal maps. Moreover, this temporal relationship is an attribute of the inhibitor-US association, not a property of either the inhibitor or the US alone. There is surely more to be learned about the encoding of temporal relationships. Here, we have treated the inhibitor, training excitor, and US as monolithic events. Each of these events could, in principle, be decomposed into stimulus onset, stimulus presence, and stimulus offset, each with its own relationship to each of the other temporal component of the other events (e.g., Romaniuk \& Williams, 2000). However, given the very short duration of our US and the moderately short durations of our inhibitor and training excitor in these experiments, we suspect that there is little temporal decomposition of these event representations in the present situation.

More generally, we suggest that subjects encode not only when the reinforcer should have occurred, were it to have occurred, but also where it would have occurred. The present experiments did not address the spatial issue, but there is considerable published data suggesting that associations encode the spatial, as well as the temporal, location of an expected US. For example, the approach/withdrawal measure of conditioned inhibition developed by Wasserman, Franklin, and Hearst (1974) provides evidence that subjects encode where an omitted reinforcer would have occurred, were it to have occurred. Thus, both excitatory and inhibitory associations might be viewed not as simple links between the representations of two paired stimuli (i.e., traditional associations), but as links that include both the temporal and the spatial relationships between the events.

\section{REFERENCES}

Barnet, R. C., Arnold, H. M., \& Miller, R. R. (1991). Simultaneous conditioning demonstrated in second-order conditioning: Evidence for similar associative structure in forward and simultaneous conditioning. Learning \& Motivation, 22, 253-268.

Barnet, R. C., Cole, R. P., \& Miller, R. R. (1997). Temporal integration in second-order conditioning and sensory preconditioning. Animal Learning \& Behavior, 25, 221-233.

Barnet, R. C., \& Miller, R. R. (1996). Temporal encoding as a determinant of inhibitory control. Learning \& Motivation, 27, 73-91.

Cole, R. P., Barnet, R. C., \& Miller R. R. (1995). Temporal encoding in trace conditioning. Animal Learning \& Behavior, 23, 144-153.

ColwIll, R. M. (1991). Negative discriminative stimuli provide information about the identity of omitted response-contingent outcomes. Animal Leaning \& Behavior, 19, 326-336.

Denniston, J. C., Blaisdell, A. P., \& Miller, R. R. (1998). Tempo- 
ral coding affects transfer of serial and simultaneous inhibitors. Animal Learning \& Behavior, 26, 336-350.

Denniston, J. C., Cole, R. P., \& Miller, R. R. (1998). The role of temporal relationships in the transfer of conditioned inhibition. Journal of Experimental Psychology: Animal Behavior Processes, 24, 200-214.

HEARST, E. (1972). Some persistent problems in the analysis of conditioned inhibition. In R. A. Boakes \& M. S. Halliday (Eds.), Inhibition and learning (pp. 5-39). London: Academic Press.

Holland, P. C., Hamlin, P. A., \& Parsons, J. P. (1997). Temporal specificity in serial feature positive discrimination learning. Journal of Experimental Psychology: Animal Behavior Processes, 23, 95-109.

Honig, W. K. (1981). Working memory and the temporal map. In N. E. Spear \& R. R. Miller (Eds.), Information processing in animals: Memory mechanisms (pp. 167-197). Hillsdale, NJ: Erlbaum.

Lubow, R. E., \& Moore, A. U. (1959). Latent inhibition: The effect of nonreinforced preexposure to the conditioned stimulus. Journal of Comparative \& Physiological Psychology, 52, 415-419.

Matzel, L. D., Held, F. P., \& Miller, R. R. (1988). Information and the expression of simultaneous and backward associations: Implications for contiguity theory. Learning \& Motivation, 18, 319-342.

Miller, R. R., \& BARnet, R. C. (1993). The role of time in elementary associations. Current Directions in Psychological Science, 2, 106-111.
Pavlov, I. P. (1927). Conditioned reflexes (G. V. Anrep, Trans.). London: Oxford University Press.

Rescorla, R. A. (1969). Pavlovian conditioned inhibition. Psychological Bulletin, 72, 77-94.

RESCORLA, R. A. (1971). Summation and retardation tests of latent inhibition. Journal of Comparative \& Physiological Psychology, 75, 77-81.

Romaniuk, C. B., \& Williams, D. A. (2000). Conditioning across the duration of a backward conditioned stimulus. Journal of Experimental Psychology: Animal Behavior Processes, 26, 454-461.

Savastano, H. I., \& Miller, R. R. (1998). Time as content in Pavlovian conditioning. Behavioural Processes, 44, 147-162.

Sмiтh, M. C. (1968). CS-US interval and US intensity in classical conditioning of the rabbit's nictitating membrane response. Journal of Comparative \& Physiological Psychology, 66, 679-687.

Wasserman, E. A., Franklin, S. R., \& Hearst, E. (1974). Pavlovian appetitive contingencies and approach vs. withdrawal to conditioned stimuli in pigeons. Journal of Comparative \& Physiological Psychology, 86, 616-627.

(Manuscript received September 12, 2000; revision accepted for publication April 11, 2001.) 